УДК 378

\title{
Н.С. Авдонина
}

\section{ОРГАНИЗАЦИОННО-ПЕДАГОГИЧЕСКИЕ УСЛОВИЯ ФОРМИРОВАНИЯ ПРОФЕССИОНАЛЬНОЙ ИДЕНТИЧНОСТИ БУДУЩИХ ЖУРНАЛИСТОВ В СИСТЕМЕ ЛИБЕРАЛЬНОГО ОБРАЗОВАНИЯ}

Проблема профессиональной идентичности обучающихся по направлению подготовки «Журналистика» обретает в последнее время все большую актуальность в связи технологическими изменениями, воздействующими на профессиональную деятельность. Современная журналистика роботизируется, происходит разделение человеческого и машинного труда в профессии. Изменения в индустрии влекут за собой пересмотр образовательного процесса на содержательном и организационном уровнях. В статье обосновывается модель организационнопедагогических условий, способствующих формированию профессиональной идентичности будущих журналистов в системе либерального образования. В связи с актуальностью аналитической и публицистической журналистики для овладения этими направлениями необходимы методики из системы либерального образования: углубленное чтение, работа с текстами, свободное письмо. В статье представлена и проанализирована система организационно-педагогических условий формирования профессиональной идентичности будущих журналистов, обучающихся по системе либерального образования в САФУ имени М.В. Ломоносова.

Ключевые слова: профессиональное образование, журналистское образование, либеральное образование, профессиональная идентичность, личностно-деятельностный подход.

DOI: $10.35634 / 2412-9550-2020-30-3-307-312$

Вопрос о формировании профессиональной идентичности будущих журналистов сегодня обретает актуальность по ряду обстоятельств. На профессию влияет научно-техническая революция: часть функций от журналистов переходит роботам. Конкуренцию официальным СМИ составляют медиапроекты, блогеры, инфлюенсеры (лидеры мнений, ставшие популярными и известными без поддержки, но за счет своей позиции, своего стиля). Цель профессиональной идентификации заключается в формировании образа «Я»-профессионала в профессиональном обучении и трудовой деятельности. Как видим, на формирование профессиональной идентичности оказывают влияние профессиональная подготовка и непосредственно работа, поэтому необходимо учитывать изменения в образовательной и профессиональной сферах. Современный мир отличается большей сложностью и неопределенностью, сегодня звучат слова «персонализированный», «индивидуальный подход» не только в производстве, но и в образовании. Сама модель образования перестраивается, включая теперь, помимо стандартных и официальных институтов, такие гибридные формы, как онлайнплатформы, образовательные форумы, мобильные приложения, «точки кипения» и др.

Первые образовательные стандарты высшего профессионального образования были приняты в 1994 г. Каждые последующие пять лет стандарты пересматривались и сменялись новыми поколениями, которые содержали требования не только к организации образовательного процесса, но и к его содержанию [11]. С 2007 г. утверждены и действуют стандарты третьего поколения, предоставляющие свободу образовательным организациям в проектировании образовательных программ. В целом переход на стандарты нового поколения свидетельствует о попытке найти баланс между теоретическим и практико-ориентированным обучением, знаниевым и деятельностным подходами. Университеты получили больше свободы в наполнении содержания образовательных программ, что позволяет разрабатывать и предлагать обучающимся оригинальные и тематические программы. Для ориентира Министерством труда РФ были утверждены профессиональные стандарты, отражающие тенденции на рынке профессий. Профессиональные стандарты также соответствуют компетентностному подходу, поскольку перечисленные обобщенные трудовые функции и трудовые действия сформулированы на основе необходимых компетенций.

Принятие профессиональных стандартов, с одной стороны, позволяет говорить о конкретизации профессии, в которой выделяются такие четкие на первый взгляд роли, как корреспондент средств массовой информации, специалист по производству продукции телерадиовещательных средств массовой информации, редактор средств массовой информации, специалист по производству продукции печатных средств массовой информации и др. С другой стороны, особенностью современной журна- 
листики является универсальность тематики, компетенций, поэтому, на наш взгляд, важно определить функционально-ролевое ядро профессии. Периодические реформы в образовании также влияют на процесс формирования профессиональной идентичности обучающихся: они становятся заложниками конкретных учебных планов, рабочих программ и формального соответствия требованиям.

Исследование, посвященное вопросу профессиональной подготовки, всегда обращено к перспективному, будущему образу профессионала. В связи с этим профессиональное образование мы рассматриваем как процесс становления и конструирования себя как профессионала. Образование в таком понимании не должно быть механическим или теоретическим, но должно предусматривать разнообразие педагогических подходов и технологий. В созидающей образовательной среде образ студента-журналиста, принимающего от преподавателя знания и умения, сменяется образом личности будущего профессионала, которая активно включена в формирование компетенций и в целом профессиональное становление в университете.

Интерес к журналистскому образованию остается актуальным по ряду обстоятельств. В ситуации «конца журналистики» [9] особенно актуальны вопросы о миссии профессии, ее функциях и методах, о содержании профессионального журналистского образования в целом. Во-первых, профессия журналиста как никакая другая испытывает на себе влияние информационно-коммуникационных технологий. Во-вторых, постепенно меняется портрет аудитории. В-третьих, изменяются и появляются новые каналы доставки и распространения информации. В-четвертых, происходит трансформация системы жанров, в научный и профессиональный лексикон входит понятие «формат». На профессиональное образование в целом влияет макросреда, что включает требования и запрос со стороны государства и общества; мезосреда представлена запросом университетов и работодателей; и микросреда, что подразумевает под собой мотивы и потребности абитуриентов и обучающихся.

Анализируя исследования, посвященные вопросу формирования профессиональной идентичности студентов-журналистов $[1 ; 4 ; 6 ; 7 ; 14]$, мы приходим к выводу, что многие исследователи опираются на идеи гуманизации и демократизации высшего образования, что соответствует фундаментальным основам и принципам журналистской профессии, а также предполагает внедрение личностно-деятельностного подхода. Тенденция гуманизации соотносится с технократической парадигмой современной журналистики. Важно не столько научить обучающихся владеть инструментами и азами создания текстов в различных форматах (что скорее относится к ремесленной стороне профессии), сколько сделать их авторами и редакторами, научить разрабатывать оригинальные медиапроекты; для этого необходимо решить проблему организации педагогического процесса, направленного на обучение и воспитание такого журналиста.

Демократизация образования способствует формированию открытого общества [12], что делает более открытой среду, в которой живет и развивается индивид. Как отмечает Е.В. Пискунова, важным аспектом демократизации жизни современного общества является «увеличение свободы человека...и повышение ответственности за себя, свою семью, свое сообщество и мир в целом» [12]. Следует отметить, что понятия «свобода» и «ответственность» всегда находятся в сопряжении. Свобода при неумелом применении воспитательных и обучающих форм, методов и средств может перейти в попустительство, а ответственность может стать синонимом обязательства, долга и вынужденной необходимости.

Гуманистическая парадигма и демократизация образования создают условия для внедрения системы либерального образования, методики которого, а именно аналитическое письмо, углубленное, медленное чтение и совместная работа над медиапроектами, способствуют формированию профессиональной идентичности будущих журналистов, готовых работать в новых условиях цифрового общества. Философия либерального образования - это философия демократического общества, в котором гражданственность, социальная ответственность и сообщество сосуществуют нераздельно.

С 1999 г. в ряде российских университетов образовательный процесс строится по системе (модели) либерального образования. Критическое мышление, свободное выражение собственного мнения, участие в открытом демократическом обществе, желание учиться в течение всей жизни - это основные результаты обучения по системе либерального образования $[5 ; 10 ; 13 ; 15]$. Данную систему отличают интерактивные методики преподавания, углубленное прочтение текстов, совместные с преподавателем проекты, гибкий учебный план, в соответствии с которым студентам предоставляется право выбора между «мэйджорами» и «майнорами» (реализация принципа междисциплинарности), основной и дополнительной специализациями.

Цель статьи - формулировка и анализ организационно-педагогических условий формирования 
профессиональной идентичности будущих журналистов в системе либерального образования. Гипотеза исследования: мы полагаем, что система либерального образования, в которой осуществляется профессиональная подготовка будущих журналистов, предполагает особые организационнопедагогические условия формирования профессиональной идентичности обучающихся. Мы рассматриваем личностно-деятельностный и контекстно-компетентностный подходы как основу организации образовательного процесса, направленного на формирование профессиональной идентичности будущих журналистов. Личностно-деятельностный подход можно рассматривать как ведущий в контексте тенденций гуманизации и демократизации, в реализации системы либерального образования, в рамках которой учитывается цель - предоставление возможности самореализации обучающемуся через деятельное участие в образовательном процессе. Личностно-деятельностный подход был разработан в середине 1980-х гг. и был направлен на развитие предметной и коммуникативной компетентности обучающегося и его личности [8]. В рамках данного подхода личность рассматривается как активный субъект деятельности, который развивается благодаря этой деятельности и общению с коллегами и меняет деятельность под себя (Л.С. Выготский, А.Н. Леонтьев, С.Л. Рубинштейн, В.Г. Ананьев и др.). Здесь важно отметить закономерность влияния личности на деятельность и деятельности на личность. Поэтому в процессе профессиональной подготовки учитываются личностные характеристики обучающихся через призму характеристик журналиста и журналистской деятельности. Цель профессионального журналистского образования - насытить личность профессионально важными качествами, ценностями, позволить найти свой личностный смысл в осуществляемой профессиональной деятельности, что закладывает основы для формирования профессиональной идентичности.

Личностно-деятельностный подход вкупе с контекстно ориентированным подходом предлагают студентам больше возможностей и свободы для самостоятельной оценки или рефлексии самих себя. Субъект-субъектные отношения предполагают, что преподаватель привлекает обучающихся к разработке методик оценивания сформированности своих компетенций, а значит, студентам можно предлагать самим разрабатывать задания, в выполнении которых студенты будут заинтересованы.

C учетом вышеизложенного мы предприняли попытку разработать структурно-логическую систему организационно-педагогических условий формирования профессиональной идентичности будущих журналистов, обучающихся по системе либерального образования в САФУ им. М.В. Ломоносова (табл.). Поясним содержание таблицы.

Целевой блок. В данной модели целевой блок имеет два вектора - тактические и стратегические цели. Тактические цели ставят перед собой педагоги и обучающиеся. Это могут быть цели обучения конкретным профессиональным знаниям, умениям и навыкам, формирования того или иного уровня профессиональной идентичности; цели воспитания убеждений, передачи и принятия профессиональных ценностей и ценностных ориентаций. Стратегические цели определяют государственные и социальные институты, работодатели. Эти цели обусловлены изменениями в мире и самих профессиях.

В структуре профессиональной идентичности мы выделяем три компонента: мотивационноценностный, когнитивный и поведенческий. Перед нами стоит конкретная задача: развить эту сферу у обучающихся. Эту цель предполагается достичь внедрением ряда принципов, которые соотносятся с идеологией либерального образования и структурой профессиональной идентичности.

Содержательный блок. Содержательный блок основывается на компетенциях, перечисленных во ФГОС ВО 3++ уровня бакалавриата. Во ФГОС ВО по направлению подготовки 42.03.02. «Журналистика» (уровень бакалавриата), принятому 8 июня 2017 г., перечислены восемь универсальных и семь общепрофессиональных компетенций. Новый ФГОС $3++$ отличается от предыдущего четырьмя основными нововведениями: 1) универсальные компетенции являются одинаковыми для всех направлений подготовки; 2) компетенции не соотносятся с задачами профессиональной деятельности; 3) профессиональные компетенции формируются на основе профессиональных стандартов, анализа требований к профессиональным компетенциям, обобщения опыта, проведения консультаций с работодателями; 4) во ФГОС 3+ были перечислены виды профессиональной деятельности, в новом ФГОС 3++ это типы задач профессиональной деятельности: авторская (исчезло слово «журналистская»), редакторская, проектная (исчезло слово «аналитическая»), маркетинговая (новый тип), организационная (исчезло слово «управленческая»), социально-просветительская (исчезло слово «организаторская») и технологическая (исчезло слово «технологическая»). 


\section{Система организационно-педагогических условий формирования профессиональной идентичности будущих журналистов}

\begin{tabular}{|c|c|c|}
\hline \multirow[t]{3}{*}{ Целевой блок } & $\begin{array}{c}\text { Тактические цели } \\
\text { (обучающие и воспитательные) }\end{array}$ & $\begin{array}{c}\text { Стратегические цели } \\
\text { (социальный и государственный заказ) }\end{array}$ \\
\hline & \multicolumn{2}{|c|}{$\begin{array}{c}\text { Цель - формирование профессиональной идентичности будущих журналистов в соот- } \\
\text { ветствии с социально-экономическими, политическими, культурными, технологиче- } \\
\text { скими и другими изменениями в обществе, влияющими на профессию }\end{array}$} \\
\hline & $\begin{array}{c}\text { Задачи: } \\
\text { - развивать мотивационно- } \\
\text { ценностную сферу; } \\
\text { - развивать когнитивную сферу; } \\
\text { - развивать поведенческую сферу }\end{array}$ & $\begin{array}{c}\text { Принципы: } \\
\text { - принцип контекстного обучения; } \\
\text { - принцип профессиональной сообразности; } \\
\text { - принцип ориентации на профессиональное } \\
\text { развитие личности; } \\
\text { - принцип диалогического обучения; } \\
\text { - принцип центрации на развитие аналитиче- } \\
\text { ского и творческого мышления; } \\
\text { - принцип ценностной значимости содержания } \\
\text { образования; } \\
\text { - принцип смыслообразования; } \\
\text { - принцип преодоления трудностей }\end{array}$ \\
\hline $\begin{array}{l}\text { Содержательный } \\
\text { блок }\end{array}$ & \multicolumn{2}{|c|}{$\begin{array}{c}\text { Комплекс аудиторных и внеаудиторных занятий по формированию профессиональной } \\
\text { идентичности будущих журналистов, разработанный в соответствии с ФГОС ВО, } \\
\text { профессиональными стандартами, принципами системы либерального образования, } \\
\text { личностно-деятельностным и контекстно-компетентностным подходами }\end{array}$} \\
\hline \multirow{3}{*}{$\begin{array}{l}\text { Организационный } \\
\text { блок }\end{array}$} & \multicolumn{2}{|c|}{ Методы и технологии образовательной деятельности } \\
\hline & Аудиторные занятия & Самостоятельная работа студентов \\
\hline & $\begin{array}{l}\text { Интерактивная, проектная работа, } \\
\text { развитие критического мышления, } \\
\text { контекстное обучение }\end{array}$ & $\begin{array}{c}\text { Развитие критического мышления, задачный } \\
\text { подход }\end{array}$ \\
\hline \multirow{3}{*}{$\begin{array}{l}\text { Результативный } \\
\text { блок }\end{array}$} & \multirow{3}{*}{$\begin{array}{c}\text { Диагностика уровня сформирован- } \\
\text { ности профессиональной идентич- } \\
\text { ности }\end{array}$} & Мотивационно-ценностная сфера \\
\hline & & Когнитивная сфера \\
\hline & & Поведенческая сфера \\
\hline
\end{tabular}

В образовательной модели свободных искусств и наук одной из важнейших характеристик является междисциплинарность, которая возможна благодаря интегративному учебному плану. От педагога ожидается готовность следовать идеологии либерального образования. Реализация либерального образования основывается на применении личностно-деятельностного и контекстно-компетентностного подходов.

Организационный блок. Аудиторная работа в рамках либерального образования реализуется посредством совместной работы педагогов и студентов над общим проектом. Для достижения цели формирования профессиональной идентичности необходимо выбирать такой проект, который позволит студентам овладеть необходимыми личностными и профессионально важными качествами.

Образовательный процесс с целью формирования профессиональной идентичности следует организовать таким образом, чтобы студенты проживали учебу как событие их начинающейся профессиональной карьеры. Учеба должна стать первой ступенью в длительном процессе формирования профессиональной биографии. Чтобы достичь этого, студенты должны активно включаться в образовательный процесс, последний должен отвечать их намерениям, целям и задачам, вписываться в их систему ценностей и ценностных ориентаций, работа в университете должна восприниматься как значимый личный опыт, имеющий смысл для дальнейшей карьеры. Студенты должны стоять не на позиции сторонних наблюдателей, а быть внутри образовательного процесса. Со стороны может показаться, что описываемая модель имеет нарочито идеалистическую структуру, но из собственного опыта автор диссертационного исследования заключает: организовать и реализовать образовательный процесс не как имитацию или квазипрофессиональную деятельность возможно.

Центральным звеном представленной нами системы является комплекс методик и технологий, применяемых во время аудиторных часов и организации самостоятельной работы студентов. Для реали- 
зации образовательных целей необходимо создать определенную образовательную среду посредством реализации конкретных организационно-педагогических условий.

В либеральном образовании важно организовать самостоятельную работу студентов, чтобы развить в них чувство ответственности, самостоятельности и креативности. Важно организовать совместную с педагогами внеучебную работу, которая может решать как задачи формирования личности, гражданина страны, так и задачи представителя выбранной профессии. Педагогу следует применять интерактивные формы обучения и воспитания и технологию проектной деятельности. Среди наиболее эффективных технологий можно назвать следующие: технологии развития критического мышления, задачный подход, технологии проектной деятельности, контекстного обучения и развивающие технологии.

В качестве примера приведем организацию самостоятельной работы студентов по дисциплине «История зарубежной журналистики». Учитывая задачи и принципы, обозначенные в целевом блоке, автором был разработан читательский дневник. Он включает в себя систему заданий на различное количество баллов от 2 до 15 и одно итоговое задание (в зависимости от курса, поскольку дисциплина идет в течение трех семестров, отличаются и текущие, и итоговое задания). Все задания предполагают развитие творческого, аналитического и критического мышления, направлены на углубленную работу с текстами, вдумчивое чтение и написание собственных произведений $[2 ; 3]$.

Результативный блок. Замыкает систему результативный блок, который соотносится с компонентами профессиональной идентичности: мотивационно-ценностный, когнитивный и поведенческий. До сих пор не найдено единой формы диагностики и контроля сформированности профессиональной идентичности обучающихся по направлению журналистики. Педагог может использовать универсальные методы наблюдения, интервью, анкетирования, опросов и тестирования. Можно предложить студентам вести рефлексивный дневник и (или) собирать портфолио. Наиболее удобными и эффективными методами можно назвать интервью, наблюдение и анкетирование. В качестве основы диагностического инструментария можно взять методику Л.Б. Шнейдер.

Нами предложены три уровня сформированности профессиональной идентичности:

1. Низший: индивид только входит в профессию, знакомится с ней на теоретическом уровне, у человека формируются ожидания в отношении будущего профессионального образования и профессии в целом. Индивид приобретает базовые профессиональные навыки, но не осознает себя профессионалом в полной мере, специалистом, его или ее могут одолевать страхи и сомнения в правильности сделанного выбора.

2. Средний: индивид работает по профессии определенное время, но не до конца принимает профессиональные ценности и ценностную ориентацию за собственные убеждения.

3. Высший: человек идентифицирует себя с выбранной профессией, развивается и совершенствуется как профессионал.

В качестве вывода отметим, что формирование профессиональной идентичности должно осуществляться в комплексной системе целеполагания, содержания и организации образовательной деятельности. Центральным звеном в системе формирования профессиональной идентичности занимают организационно-педагогические условия, обеспечивающие создание определенной образовательной среды, основанной на выборе профессиональных знаний, умений, навыков, ценностей и ценностной ориентации, отборе методов и технологий обучения и воспитания, способствующих удовлетворению актуальных профессиональных потребностей студентов. Реализация на практике вышеназванных педагогических условий в системе либерального образования позволит решить задачи проводимого автором исследования.

\section{СПИСОК ЛИТЕРАТУРЫ}

1. Абишева В.Т. К проблеме изучения личности журналиста-профессионала // Актуальные проблемы гуманитарных и естественных наук. 2014. № 8. С. 196-199.

2. Авдонина Н.C. Ресурсы Google для выполнения и контроля самостоятельной работы студентов-журналистов // Новые образовательные стратегии в современном информационном пространстве: сб. науч. ст. по материалам международной научной конференции 11-12 апреля 2017 года. СПб.: Издательство РГПУ им. А.И. Герцена, 2017.

3. Авдонина Н.С. Самостоятельная работа студентов как инструмент развития компетенций студентовжурналистов // Отечественная и зарубежная педагогика. 2017. № 5. С. 184-197.

4. Аникина М.Е. Трансформирующиеся журналистские культуры в России: исследовательский подход // Вестник Московского университета. Сер. 10. Журналистика. 2012. № 4. С. 7-21 
5. Беккер Дж. Образование по системе свободных искусств и наук: ответ на вызовы XXI в. // Вопросы образования. 2015. № 4. С. 33-61.

6. Владимирова Т.Н. Дидактическая концепция профессиональной подготовки журналистов в высшей школе России: дис. ... докт. пед. наук. М., 2015. 481 с.

7. Дорощук Е.С. Проблемы профессиональной идентификации будущих журналистов в контексте образовательных траекторий // Мультимедийная журналистика Евразии - 2015: медиатизация социально-культурного пространства и медиакратия в условиях новой медиареальности Востока и Запада. Евразия молодая - 2015: сборник материалов и научных статей IX Международной научно-практической конференции. Казань, 10-11 декабря 2015 года / науч. ред. проф. Е.С. Дорощук. Казань: Изд-во Казан. ун-та, 2016. С. 88-95.

8. Зимняя И.А. Педагогическая психология: учебник для вузов. 2-е изд., доп., испр. и перераб. М.: Логос, 2000. $384 \mathrm{c}$.

9. Зорин К.А. Образование в условиях кризиса журналистики: поиски стратегии // Вестник НГУ. Сер. История, филология. 2013. Т. 12, № 6: Журналистика. С. 116-123.

10. Иванова Ю.В., Соколов П.В. Перспективы развития образования по модели свободных искусств и наук в России // Вопросы образования. 2015. № 4. С. 72-91.

11. Лаптев В.В., Писарева С.А., Тряпицына А.П. Концептуальная рамка согласования образовательных и профессиональных стандартов в программах подготовки педагогов в университете // Известия РГПУ им. А.И. Герцена. 2017. № 185. С. 5-14.

12. Пискунова Е.В. Социокультурная обусловленность изменений профессионально-педагогической деятельности учителя: монография. СПб.: Изд-во РГПУ им. А.И. Герцена, 2005. 324 с.

13. DeNicola D. Learning to flourish. A philosophical exploration of liberal education. New York: Continuum International Publishing Group, 2012. 270 p.

14. Hujanen J. Renegotiating the Journalism Profession in the Era of Social Media: The Case of Northern and Southern Journalism Students // Journalism and Mass Communication Educator. 2018. PP. 1-11.

15. Tubbs N. Philosophy and Modern Liberal Arts Education. Freedom is to Learn. London: Palgrave Macmillan. 2014. $204 \mathrm{p}$.

Поступила в редакцию 01.02.2020

Авдонина Наталья Сергеевна, кандидат политических наук, доцент, доцент кафедры журналистики, рекламы и связей с общественностью

Северный (Арктический) федеральный университет им. М.В. Ломоносова

163002, Россия, г. Архангельск, набережная Северной Двины, 17

E-mail: natalia.avdonina1987@gmail.com

\section{N.S. Avdonina \\ ORGANIZATIONAL AND PEDAGOGICAL CONDITIONS FOR THE FORMATION OF PROFESSIONAL IDENTITY OF FUTURE JOURNALISTS IN THE SYSTEM OF LIBERAL EDUCATION}

DOI: $10.35634 / 2412-9550-2020-30-3-307-312$

The problem of professional identity of students in the field of "Journalism" has recently become increasingly relevant in connection with technological changes affecting the professional activity. Modern journalism is being robotized, there is a separation of human and machine labor in this profession. Changes in the industry entail a review of the educational process at the substantive and organizational levels. In this regard, the article substantiates a model of organizational and pedagogical conditions that contribute to the formation of professional identity of future journalists in the system of liberal education. We proceed from the provision on robotization of news journalism, therefore, analytical and publicistic journalism will become relevant, and for training in these areas liberal education methods are needed in-depth reading, working with texts, free writing. The article presents and analyzes the system of organizational and pedagogical conditions for the formation of professional identity of future journalists studying in the liberal education system at NArFU named after M.V. Lomonosov.

Keywords: professional education, journalism education, liberal education, professional identity, personal-activity approach.

Received 01.02.2020

Avdonina N.S., Candidate of Political Science, Associate Professor at Department of Journalism,

Advertisement and PR

Northern (Arctic) Federal University named after M.V. Lomonosov

Severnaya Dvina emb., 17, Arkhangelsk, Russia, 163002

E-mail: natalia.avdonina1987@gmail.com 